\title{
TRUST WHEN FINANCIAL IMPLICATIONS ARE NOT THE AIM: THE INTEGRATION OF SUSTAINABILITY INTO MANAGEMENT EDUCATION
}

\author{
Blanca L. DELGADO-MÁRQUEZ ${ }^{1}$, J. Alberto ARAGÓN-CORREA ${ }^{2}$, \\ Eulogio CORDÓN-POZO ${ }^{3}$, Luis Enrique PEDAUGA ${ }^{4}$ \\ ${ }^{1}$ Department of International and Spanish Economics, University of Granada, \\ Campus de la Cartuja, s.n. E-18071, Granada, Spain \\ ${ }^{2}$ The Surrey Business School. Faculty of Business, Economics and Law, University \\ of Surrey, GU2 7XH, Guildford \\ ${ }^{3}$ Department of Management, University of Granada, Campus de la Cartuja, \\ s.n. E-18071, Granada, Spain \\ ${ }^{4}$ Department of Economics, University of Granada, Campus de la Cartuja, \\ s.n. E-18071, Granada, Spain. \\ E-mails: ${ }^{1}$ bdelgado@ugres (corresponding author);

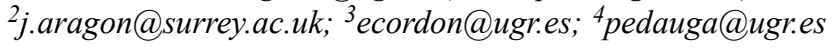

Received 13 March 2014; accepted 27 April 2015

\begin{abstract}
Literature has paid detailed attention to the positive financial implications of considering the stakeholders' environmental concerns. This paper contributes by using a trust framework to delimitate how stakeholders may influence managers' environmental decisions even if they are not focused on financial objectives. Specifically, we analyse how perceptions of academic department heads about their stakeholders' ability and benevolence influence the head's willingness to integrate sustainability issues into the syllabus of the courses. We also investigate the direct and moderating role of the heads' interest in financial aims and the direct influence of the school environmental proactivity. Our analysis includes a sample of 74 deans in 46 different business and engineering schools and a sample of 95 department heads in the field of management studies of 25 Spanish universities. The hierarchical moderated regression results confirm the positive influence of the ability and benevolence of the stakeholders and the heads' interest in the financial aims, but not the moderating effects and the influence of the school proactivity. The paper provides research implications on the stakeholders' dimensions influencing environmental decisions and practical implications showing that managers of organisations who wish to advance their environmental approaches may use partnerships with their stakeholders based upon trust.
\end{abstract}

Keywords: Trust, ability, benevolence, stakeholders, sustainability, management education.

JEL Classification: M21, I21, I23. 


\section{Introduction}

Previous literature has focused on the power of certain stakeholders to influence the environmental decisions of the organisation and their economic implications on the organisation (e.g., Aragón-Correa et al. 2013; De Lange 2013). Although Mitchell et al. (1997) proposed that stakeholders have additional forms of power apart from economic influence, the previous literature on organisations and the natural environment has paid little attention to whether and how stakeholders influence environmental progress in organisations when the people in charge of making environmental decisions do not perceive financial issues as the main aim of the organisation. Such is the case of universities, in which managers deciding on the embeddedness of sustainability content generally focus on academic issues and do not prioritise financial aspects (De Paola 2011).

The importance of sustainability in education has been widely recognised (e.g. Koehn and Uitto 2014 for additional review). Nonetheless, recent literature has noted the need to carry out empirical research to clarify the adoption of sustainability in business university curricula (De Lange 2013; Rusinko 2010; Sharma 2013). This paper explores this area of interest to show that the managers' perceptions regarding the trustworthiness of the organisational stakeholders may influence their decisions regarding the integration of environmental issues into the syllabus of the management courses even in the absence of financial incentives to do so.

The trust literature proposes that decisions taken by certain people - trustors - involve a risk level that depends on other people to whom the decision is related - trustees (Rousseau et al. 1998; Schoorman et al. 2007). Thus, trustors are prepared to act if they perceive that trustees present a sufficient degree of trustworthiness (i.e., ability, integrity and benevolence), in order for the risk inherent in the decision to be lower than the potential benefits. Nonetheless, no attention has yet been paid to analysing the role of managers' trust placed in the stakeholders on making environmental decisions.

There are at least three practical reasons for why this analysis of the integration of content related to sustainability (Brundtland Report 1987) in university courses is important. First, the trust literature offers the possibility of analysing the stakeholders' influence on managers with independence from the financial implications. In this context, the career development of scholars deciding on the degree of sustainability of their teaching is not usually linked to the financial performance of the organisation (De Paola 2011), and it is important to propose a different framework for these decision makers. Second, this analysis is of relevance because it provides insight about how higher education stakeholders may promote the embeddedness of sustainability content in university education. Given the importance of students acquiring skills related to sustainability, which can be used in their subsequent professional lives as managers (e.g., Coleman 2013; Sharma, Hart 2014; Slater, Dixon-Fowler 2010), it is of interest to define ways of influencing the integration of sustainability into management education. Third, this paper addresses the role of financial aims in the organisation when they are not a priority and - more generally - the contingent influence of the school in the decisions related to the embeddedness of sustainability content. 
The paper is structured into five sections following this introduction. In the next section, a review of the literature on trust is developed. We present research hypotheses in the third section. The fourth section covers the methodology and section five the results obtained. Finally, we conclude with the contributions, implications, limitations and future research.

\section{Theoretical background: trust}

The literature on trust has focused on determining the factors influencing a person's willingness to make a decision, knowing that the final benefits depend on the behaviour or attitude of other people (Schoorman et al. 2007).

Rousseau et al. (1998) define trust as a psychological state comprising the intention to accept vulnerability based on positive expectations regarding the intentions or behaviour of others. The three factors that have been repeatedly identified as explaining the decision to trust are the trustor's perception of the ability, integrity and benevolence of the trustee (Mayer et al. 1995). Ability refers to the group of skills, competencies and characteristics that enable a party to have influence within some specific domain. Furthermore, the relationship between integrity and trust involves the trustor's perception that the trustee adheres to a set of principles that the trustor finds acceptable. Finally, benevolence is the extent to which the trustee is believed to desire to do positive things for the trustor (Tomlinson, Mayer 2009).

Trustworthiness is the trustor's perception regarding these three dimensions of the trustee - ability, integrity and benevolence (Mayer et al. 1995) - and is the key antecedent of trust in the related literature (Schoorman et al. 2007; Serva, Fuller 2004). Trust would be unnecessary if actions could be undertaken without risk (Uslaner 2013).

The literature on trust has highlighted that the analysis of integrity has special interest in profit-oriented contexts (e.g., Kerler, Killough 2009) where trustees have financial incentives to act with a lack of integrity. Because the trust literature has emphasised the importance of considering relevant dimensions depending on the specific context analysed (Serva, Fuller 2004), we investigate only those trustworthiness dimensions that seem more relevant in our context: ability and benevolence. Particularly important is to recognise that the literature on trust has paid far less attention to the dimension of benevolence, and there have been calls specifically to integrate this dimension (Schoorman et al. 2007).

\section{The integration of sustainability: hypotheses}

\subsection{Sustainability and research model}

Sustainability refers to meeting the needs of the present generation without compromising the ability of future generations to meet theirs (Brundtland Report 1987). In this vein, organisations have come under increasing pressure from several stakeholders to address the economic, environmental and social implications of their activities (Ching, Moreira 2014). 


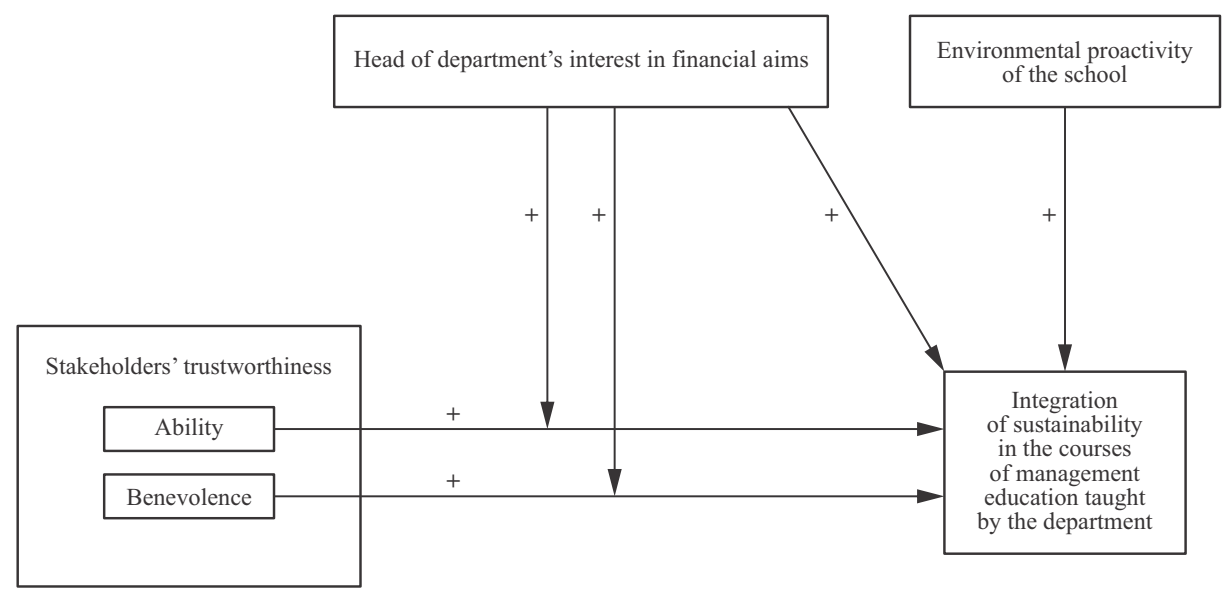

Fig. 1. Research model proposed

Over the last few years, various international forums have highlighted the importance of integrating knowledge to facilitate sustainability in higher education (e.g. UNESCO 2002) in general, and in management courses in particular (Montgomery, Ramus 2011; Stead, J. G., Stead, W. E. 2010). In our paper, the integration of sustainability into management courses refers to the incorporation of different types of content that will enable future managers to understand better the repercussions of their future professional activity for the next generations (De Lange 2013).

Figure 1 establishes the relationships analysed in this paper.

\subsection{The influence of stakeholders' trustworthiness}

\subsubsection{The perception of stakeholders' ability}

Ability is that group of skills, competencies and characteristics that enable a party to have influence within some specific domain (Mayer et al. 1995: 717). Ability is always studied for specific domains because, for example, a trustee may have a high ability to collaborate in the integration of sustainability into management courses, but may have a reduced ability to collaborate with the integration of a specific programming language. Literature on stakeholders applied to environmental issues has shown that managers' perceptions regarding stakeholders are directly related to the corporate environmental commitment and practices (Henriques, Sadorsky 1999; Sharma, Henriques 2005)). Moreover, recent works have stressed the potential of stakeholders' collaboration and behaviour to influence firms' environmental strategy (Aragón-Correa et al. 2013; Darnall, Aragón-Correa 2014). In a study of university management, Lounsbury (2001) found that the integration of environmental management on campuses can be linked to students' skills to provide effective collaboration regarding this issue.

We contend that the head of department's perception of the ability of the organisation's stakeholders to collaborate in the integration of environmental sustainability allows the head to reduce the risks of the decision made in at least three ways. First, the ability 
of stakeholders in the area requires less effort by the head of department in explaining the objectives pursued. Second, the ability of stakeholders increases the chances of successful implementation and reduces the need for prior investment. Finally, this ability enables stakeholders to understand more easily the problems that may arise in the process and, possibly, to evaluate a potential error less negatively. Therefore, we propose the following hypothesis:

H1a: Stakeholders' ability in the sustainability issues perceived by the head of department positively affects the head's intention to integrate those issues into departmental courses.

\subsubsection{The perception of stakeholders'benevolence}

Benevolence is defined as the extent to which the party is believed to desire to do positive things for the trustor (Tomlinson, Mayer 2009: 86). Unlike what occurs with the dimensions of ability and integrity, the perception of the trustee's benevolence is usually developed after a continuing relationship between trustor and trustee (Mayer et al. 1995), as is the case of the relationships analysed in this paper.

In fact, stakeholders' benevolence facilitates the decision of the departmental head to trust them through two main ways. First, the stakeholder is open to the guidance considered suitable by the head of department, which reduces the effort involved in justifying the decisions and obtaining the stakeholder disinterested collaboration in the integration of sustainable dimensions. Second, a benevolent stakeholder is more understanding in relation to potential failures or disruptions in the system as a consequence of the focus on sustainability issues because he or she is able to empathise with the head of department, even though no gain is involved. Taking this as a basis, we postulate the following hypothesis:

H1b: Stakeholders' benevolence perceived by the head of department positively affects the head's intention to integrate sustainability issues into departmental courses.

\subsection{The decision makers' interest in the economic objectives of their organisation}

\subsubsection{The direct influence}

Paying attention to stakeholders' interest in environmental issues enables organisations to increase financial profitability (Berman et al. 1999; Hart 1995). Therefore, heads who are keenly interested in the financial objectives of their departments may be more willing to incorporate sustainability issues in the department's courses. Also, heads of management departments may be familiar with the potential of environmental issues to increase the reputation and legitimacy of organisations (Hart 1995), both of which may be useful tools in seeking extra financial support for the department. Even in organisations that do not aim to achieve higher profitability, financial issues may be particularly important. For example, heads of university departments manage a budget that serves to meet the equipment needs of their faculty, to pay guests' expenses or to provide a travel budget to the departmental scholars. Nonetheless, the importance given by the head of department to financial issues may depend on multiple factors (e.g., the characteristics of the decision maker, the context, the professors' needs, the lack or abundance of bud- 
get). In any event, an interest in financial issues will make the head of department more interested in practices that can influence the financial situation of the department. This gives rise to the following hypothesis:

H2: The departmental head's interest in the financial aims of the organisation positively influences his or her intention to integrate sustainability issues into departmental courses.

\subsubsection{The moderating influences}

Although different studies have shown the moderating effects of managers' perceptions on the integration of sustainability in organisations (Henriques, Sadorsky 1999) and on the relationship between stakeholder concerns and the firm's environmental strategy (Kassinis, Panayiotou 2006), the moderating effect of the importance for managers of financial issues on the relationship between stakeholder trustworthiness and the integration of sustainability has not yet been studied. We drew upon this literature to propose that the head of department's interest in financial aims moderates the relationship between two dimensions of trustworthiness (i.e., ability and benevolence) and the integration of sustainability into management education courses.

The literature on organisations and the environment shows that improved financial performance usually accompanies proactive environmental strategies that exceed regulatory requirements (Russo, Fouts 1997). If the decision maker is aware that the development of proactive environmental strategies is usually accompanied by an increase in financial performance, the greater interest in financial targets can be expected to reinforce the positive relationship between the perceived ability of the stakeholders and the integration of environmental issues into the organisation.

This moderation emerges because an interest in financial objectives reduces the perceived risk inherent in the integration of environmental issues. For example, if the head of department feels that the stakeholders' ability is very high, a high degree of interest of the head of department in financial targets will increase the likelihood of integrating sustainability into the management courses because an empirical relationship has been proved to exist between developing a proactive environmental strategy and improving financial performance. Moreover, the head of department feels that stakeholders have the skills to work competently in this integration. Hence, we propose the following hypothesis:

H3a: The departmental head's interest in financial targets positively moderates the relationship between stakeholders' ability perceived by the head of department and the head's intention to integrate sustainable contents into departmental courses.

We also propose that the interest of the decision maker in the organisation's financial goals exerts a moderating effect on the relationship between departmental head's interest in financial targets and his/her perception of the stakeholders' benevolence. The stakeholders' benevolence reduces the perceived risk of trusting them as partners in the process of integrating sustainability into management education courses. Then, a high departmental head's interest in the financial objectives makes the decision to integrate 
sustainability more appealing to the head of department because the interest of the financial rewards reinforces his/her interest in the benevolence potential. Similarly, a low departmental head's interest in the financial objectives reduces the relationship between perceived stakeholders' benevolence and the integration of environmental issues because of the limited potential of rewards. This gives rise to the following hypothesis:

H3b: The departmental head's interest in financial targets positively moderates the relationship between stakeholders' benevolence perceived by the head of department and the head's intention to integrate sustainable contents into departmental courses.

\subsection{The influence of the environmental proactivity of the school}

In the organisation and natural environment literature, literature has shown how exogenous factors influence managers' decisions regarding the natural environment (e.g., Russo, Fouts 1997). Contingent factors also influence the relationship between managers' perception regarding the firm's stakeholder integration capability and its environmental strategy (Sharma et al. 2007).

Additionally, organisations vary according to how environmentally proactive they are (Aragón-Correa 1998). Ramus and Steger (2000) also show how management support behaviours are positively related to employee "ecoinitiatives".

As a result, we propose that the decisions of the heads of departments to integrate sustainability issues in the curricula of the courses are positively influenced by the environmental approach of their schools. Proactive environmental schools may provide inspiration, legitimating effects, or illustrations to heads of departments to offer more sustainable content. Hence, this leads to the following hypothesis:

H4: Proactive environmental strategies of schools positively influence the intention of the heads of department to integrate sustainability issues into departmental courses.

\section{Methodology}

\subsection{The context of the analysis}

Each university may have a different system depending on the person who can decide on a systematic integration of sustainability into courses. All the universities in our sample state that, although the heads of department decide upon the final content of the courses, the dean plays a symbolic role, suggesting ideas for courses, promoting the general direction of the programme and managing the school.

Before analysing our hypotheses, we attempted to understand better the context in which the sampled heads of departments make decisions. To this end, we sent a written questionnaire to 164 deans of business and engineering education schools in 69 Spanish universities to gather their perceptions regarding the economic benefits a proactive environmental strategy could provide to the centre. The final deans' dataset comprised 74 deans of 46 different universities, accounting for $66.67 \%$ of the management and engineering schools and $45.12 \%$ of the deans surveyed. 
The environmental proactivity of each school was measured by an arithmetic mean of 13 items that captured various environmental practices and their degree of implementation in the centre, measured using a Likert scale from 0 to 6 points, in which higher scores meant a higher degree of proactivity (see supplemental material for a list of all the items in the paper). The perceived economic advantages were calculated by using a variable comprising three items related to improvements in student demand, revenue or cost reduction measures, also by means of a 7-point Likert scale from 0 to 6 . The measures enabled us to classify the schools into three groups in relation to their degree of environmental development according to a confidence interval on the mean at $95 \%$.

\subsection{Sample}

The sample used to test the model and hypotheses proposed comprises 95 heads of department whose courses are integrated into the master's programmes of business schools and engineering education centres at 25 Spanish universities.

The sample was obtained by means of a written questionnaire sent on three occasions by both regular mail and email to the heads of the departments with the option to reply online or on paper. The total population that received the questionnaire comprised 224 heads of department from Spanish universities. After a response rate of $42.41 \%$ of department heads surveyed, the final sample comprised 95 heads of department whose courses are integrated into the master's programmes of business schools and engineering education centres at 25 Spanish universities. These results imply a representativeness of $42.41 \%$ for the department heads and of $35 \%$ for the Spanish universities surveyed. This rate of response can be considered highly satisfactory in comparison with the usual response rates in such studies. Furthermore, no significant differences were found in the size of the universities that responded to the questionnaire. Additionally, no significant differences were found in the replies to the questionnaire in the first round in relation to the third round or between online or postal replies.

We also followed a detailed pattern in our work (Podsakoff et al. 2003) to reduce the potential risk of common method biases as much as possible. Finally, it is important to note that all the departments in our sample had a similar low level of involvement of previous environmentally sustainable topics in their courses. Consequently, the perceptions considered were unlikely to have been influenced by this issue.

\subsection{Measures}

In line with the literature, we measured the different constructs using multi-item scales (e.g., DeVellis 2003). Analyses were conducted with the Mplus 7.2 package using the WLSMV estimation method, which is suitable when variables are ordinal and the sample size is relatively small (Wang, J., Wang, X. 2012). If the scale comprised less than three items, Cronbach's alpha coefficient was used as an indicator of scale reliability (Peterson 1994). See supplemental material for more detail.

Integration of sustainability into management education. We asked respondents to describe their willingness to integrate in the future seven different issues related to sustain- 
ability in the syllabuses of the courses taught by their departments (regulatory approaches, ethics, management systems, waste, energy saving, responsible use of technology and economic implications). Our final measure was the arithmetic mean of their replies to seven items based upon a Likert scale from 1 to 5 , where higher values indicate more advanced intentions regarding the integration of environmental topics.

Perceived stakeholder ability. The measurement of this variable was built upon the definition of ability provided in Mayer et al. (1995). Specifically, we used a set of items to gather the heads of departments' perceptions regarding the stakeholders' ability to cooperate fruitfully in the integration of sustainable teaching into management education. We used a Likert scale from 0 to 6 , in which higher values reflect a high perceived ability of each stakeholder. The final measure was the arithmetic mean of the six items proposed.

Perceived stakeholder benevolence. The procedure was similar to that used to evaluate ability but now focused on ascertaining the opinion of the head of department in relation to the selfless and honest cooperation he or she expected from each stakeholder (Mayer et al. 1995) with respect to the integration of sustainability into management courses. The confirmatory factorial analysis showed the goodness of fit.

Interest in financial aims. This variable measures the head of department's interest in financial issues. A Likert scale from 0 to 6 was used to evaluate five different objectives in a university department (teaching quality, research outputs, financial income, operating costs and promotion of the scholars). An exploratory factorial analysis shows the potential of the joint analysis of the two items related to financial issues (income and costs). The final measure is an arithmetic mean of these two items. A descriptive analysis showed that interest in financial issues in the department was the proposed target that scored the lowest (a mean of 3.24) for the sampled heads of department.

Proactivity of the school. Please see the context section of this paper for a detail explanation of the measurement of this variable.

Control variables. We controlled heads of departments' embedded in engineering education centres by using a binary variable, in which 0 means the head of department is embedded in a business school. We also controlled the department size through the number of students enrolled in the courses offered by the department.

\section{Results}

We conducted Harman's single-factor test by an exploratory factor analysis (EFA) with all items in the study. The results showed that there was no single factor, confirming that the common source variance is not a problem in our analysis:

Table 1 reports basic descriptive statistics and correlations. The variables present no major correlation problems.

Table 2 shows the hierarchical moderated regression analysis (Jaccard, Turrisi 2003). Model 1 provides a baseline model that includes only the control variables. Models 2 and 3 report tests of specific hypotheses. 
Table 1. Means, standard deviations, and correlations ${ }^{\mathrm{a}}$

\begin{tabular}{|c|c|c|c|c|c|c|c|c|}
\hline Variable & Mean & s.d. & 1 & 2 & 3 & 4 & 5 & 6 \\
\hline $\begin{array}{l}\text { 1. Integration of sustainability } \\
\text { in management education }{ }^{b}\end{array}$ & 2.69 & 0.92 & & & & & & \\
\hline $\begin{array}{l}\text { 2. Business school versus engineering } \\
\text { education }^{c}\end{array}$ & 0.40 & 0.49 & $-0.38^{* * *}$ & & & & & \\
\hline 3. Size & 2.45 & 8.67 & $-0.21^{*}$ & -0.12 & & & & \\
\hline 4. Environmental proactivity of the school ${ }^{\mathrm{c}}$ & 2.35 & 0.85 & 0.09 & -0.08 & 0.09 & & & \\
\hline 5. Perceived stakeholders' benevolence ${ }^{c}$ & 2.91 & 0.98 & $0.32^{* *}$ & -0.01 & $-0.08-$ & -0.00 & & \\
\hline 6. Perceived stakeholders' ability ${ }^{\mathrm{c}}$ & 2.92 & 0.93 & $0.28^{* *}$ & 0.03 & -0.11 & -0.00 & $0.20^{*}$ & \\
\hline $\begin{array}{l}\text { 7. Head of department's interest } \\
\text { in financial aims }{ }^{c}\end{array}$ & 3.45 & 1.00 & $0.21^{*}$ & 0.12 & -0.13 & -0.02 & $0.22^{*} \mathrm{C}$ & $0.17^{+}$ \\
\hline
\end{tabular}

Notes: ${ }^{\mathrm{a}} \mathrm{n}=95 ;{ }^{\mathrm{b}}$ Scale ranges from 1 to 5 ; ${ }^{\mathrm{c}}$ Scale ranges from 0 to $6{ }^{+} p<0.1 ; * p<.05 ; * * p<.01$; $* * * p<.001$.

Table 2. Results of the hierarchical moderated regression analysis ${ }^{\mathrm{a}}$

\begin{tabular}{lccc}
\hline \multicolumn{1}{c}{ Variable } & Model 1 & Model 2 & Model 3 \\
\hline Control & & & \\
Engineering education school & $-0.42(-4.31)^{* * *}$ & $-0.43(-4.91)^{* * *}$ & $-0.43(-4.81)^{* * *}$ \\
Size & $-0.27(-2.80)^{* *}$ & $-0.21(-2.40)^{*}$ & $-0.21(-2.36)^{*}$ \\
\hline $\begin{array}{l}\text { Main effects } \\
\text { Stakeholders' benevolence }\end{array}$ & $0.25(2.82)^{* *}$ & $0.24(2.69)^{*}$ \\
$\begin{array}{l}\text { Stakeholders' ability } \\
\text { Head of department's interest } \\
\text { in financial aims }\end{array}$ & $0.19(2.18)^{*}$ & $0.18(2.00)^{*}$ \\
Environmental proactivity of the school & $0.15(1.65)^{+}$ & $0.15(1.69)^{+}$ \\
\hline $\begin{array}{l}\text { Moderation } \\
\text { Stakeholders' benevolence } \times \text { Head of } \\
\text { department's interest in financial aims }\end{array}$ & $0.06(0.70)$ & $0.07(0.83)$ \\
$\begin{array}{l}\text { Stakeholders' ability } \times \text { Head } \\
\text { of department's interest in financial aims }\end{array}$ & & & $-0.03(-0.36)$ \\
\hline \multicolumn{1}{c}{$\mathrm{F}$} & $11.94 * * *$ & $8.50^{* * *}$ & $6.30^{* * *}$ \\
\hline \multicolumn{1}{c}{$\Delta \mathrm{R}^{2}$} & 0.219 & 0.386 & 0.390 \\
\hline
\end{tabular}

Notes: ${ }^{\text {a }}$ The integration of sustainability in management education is the dependent variable. The parameters estimates are standardized coefficients. The $t$-statistic for each estimate is in parentheses; ${ }^{+} p<.10 ;{ }^{*} p<.05 .{ }^{* *} p<.01 . * * * p<.001$.

The results in Model 3 show support for the Hypotheses 1a, 1b and 2. However, our results do not confirm the moderating effects of Hypotheses $3 \mathrm{a}$ and $3 \mathrm{~b}$. We believe that these results may be related to the very limited importance attributed by the heads of department in our sample to the financial objectives of the department in comparison with other more academic goals (such as improving research results, teaching quality 
improvement or promotion of department staff). This limited importance may have prevented the possibility of observing the moderating effect in the sampled organisations. Finally, results do not support Hypothesis 4 stating the positive influence of environmental proactivity of the school. Various peculiarities of the sample may explain this result. First, our sample presents a relatively well differentiated sphere of influence between the academic decisions of the department and the managerial strategies of the school. It may be that positive approaches towards the integration of sustainability at the university level are more relevant as a proxy of the context than the managerial approach in the school for the integration of sustainability content in the curricula. Second, thinking in a more critical way, the results may suggest that management of the university is not necessarily connected to the managerial education offered by the department. This result raises questions regarding the credibility of sustainability education in university management courses.

\section{Conclusions}

\section{Contributions and implications}

Our analyses provide three main theoretical contributions to the literature. First, whereas previous literature has focused on studying the influence of stakeholders' economic power, the incorporation of the variable "trust" provides an understanding of the complementary roles of stakeholders. Hence, we enrich prior research (e.g., Sharma, Hart 2014) by finding evidence about the influence of university stakeholders on the embeddedness of sustainability content into the courses. Second, our study responds to a need to extend the literature on trust beyond the supplier-customer commercial areas. The article shows the influence of the concept in more complex areas of interaction, such as those contexts that are not primarily driven by financial targets and in which trustor's decisions are influenced by multiple trustees. Our findings reveal that the existence of multiple stakeholders influencing the risk involved in a decision has a significant joint effect on a decision maker's willingness. Third, our paper contributes to the previous literature on stakeholders and the natural environment by showing that stakeholders can be important in the educational sector, although their economic influence may be limited, if they influence the risk taken by managers in their decisions.

These results may be relevant for managers who wish to advance their environmental approaches because our findings suggest that they should consider the possibility of developing a partnership with their stakeholders based upon trust. Although this recommendation is intended to be useful for any organisation, it may be especially important for non-profit organisations (e.g., educational organisations) whose managers have goals and strategies that are frequently not related to the objectives of the financial profitability of the organisation (scientific publications, reputation, increasing the number of teaching positions).

Our work underlines the importance of understanding the possibilities provided by stakeholders to reduce managerial risks in decisions that are often dependent on the behaviour and attitude of these stakeholders. In the field of management education, it is important to establish the existence of relevant stakeholders who should be taken into 
account to facilitate the integration of sustainability in the courses of the departments. Moreover, our study provides stakeholders with opportunities to influence managerial behaviour beyond the traditional approaches of financial incentive or penalty. Being viewed as a trustworthy stakeholder in the environmental context encourages the organisation responsible for making the decision to assume the level of risk this decision implies. A low level of trust by managers in the stakeholders' ability and benevolence may mean that even when managers see potentially important financial benefits in their environmental management, they would be unwilling to accept the decision due to the high level of risk involved for them.

\section{Limitations and future research}

Two limitations of this study should be recognised. The first limitation is related to the cross sectional nature of our data, which does not provide opportunity for a more definitive empirical confirmation of the bidirectionality of trust in our analysis, i.e., whether stakeholders' perceptions on the manager's ability and benevolence may also influence the stakeholders' willingness to cooperate on the integration of sustainable contents into business curricula.

Also, our geographical focus is something particularly important to keep in mind. The decision-making process (i.e., the roles assigned to deans and heads of department) by which our analysis is framed provides a country-specific perspective and may not necessarily coincide with that in other countries. Thus, there is need for caution when extrapolating our results to other countries whose decision-making mechanisms or university leadership conditions differ from those in Spain.

This paper can be complemented by two broad lines of research. First, the analysis of trust earned by stakeholders in situations in which environmental advances are compulsory constitutes an attractive field of investigation because it addresses the lack of financial incentives analysed in this paper. At any rate, the literature on the importance of trust in environmental decisions remains scarce within the context of growing concern for environmental issues, where the role of managers as responsible in this sense is becoming increasingly relevant.

Second, future research could also attempt to analyse the potential influence of the personal background of heads of department. Although the literature shows that these features play a more relevant role in the building of initial trust (Serva, Fuller 2004), it might be interesting to analyse whether certain professional, psychological or formative profiles of heads of department modify the assessment they make regarding collaboration with the stakeholders of a university department.

\section{Acknowledgements}

The authors are extremely grateful to the editor and three anonymous referees for their meaningful and constructive comments. 


\section{References}

Aragón-Correa, J. A. 1998. Strategic proactivity and firm approach to the natural environment, Academy of Management Journal 41(5): 556-567. http://dx.doi.org/10.2307/256942

Aragón-Correa, J. A.; Martín-Tapia, I.; Hurtado-Torres, N. 2013. Proactive environmental strategies and employee inclusion: the positive effects of information sharing and promoting collaboration and the influence of uncertainty, Organization \& Environment 26(2): 139-161.

http://dx.doi.org/10.1177/1086026613489034

Berman, S. L.; Wicks, A. C.; Kotha, S.; Jones, T. M. 1999. Does stakeholder orientation matter? The relationship between stakeholder management models and firm financial performance, Academy of Management Journal 42(5): 488-506. http://dx.doi.org/10.2307/256972

Brundtland Report. 1987. Our common future. The world commission on environment and development. New York, NY: Oxford University Press.

Ching, H. Y.; Moreira, M. A. 2014. Management systems and good practices related to the sustainable supply chain management, Journal of Management and Sustainability 4(2): 34-45. http://dx.doi.org/10.5539/jms.v4n2p34

Coleman, G. 2013. Sustainability as a learning challenge, Journal of Management Development 32(3): 258-267. http://dx.doi.org/10.1108/02621711311318292

Darnall, N.; Aragón-Correa, J. A. 2014. Can ecolabels influence firms' sustainability strategy and stakeholder behavior?, Organization \& Environment 27(4): 319-327.

http://dx.doi.org/10.1177/1086026614562963

De Lange, D. E. 2013. How do universities make progress? Stakeholder-related mechanisms affecting adoption of sustainability in university curricula, Journal of Business Ethics 118: 103116. http://dx.doi.org/10.1007/s10551-012-1577-y

De Paola, M. 2011. Easy grading practices and supply-demand factors: evidence from Italy, Empirical Economics 414: 227-246. http://dx.doi.org/10.1007/s00181-010-0372-9

DeVellis, R. F. 2003. Scale development: theory and applications. Thousand Oaks, CA: Sage Publications.

Hart, S. L. 1995. A natural resource-based view of the firm, Academy of Management Review 20(4): 986-1014. http://dx.doi.org/10.5465/AMR.1995.9512280033

Henriques, I.; Sadorsky, P. 1999. The relationship between environmental commitment and managerial perceptions of stakeholder importance, Academy of Management Journal 42(1): 87-99. http://dx.doi.org/10.2307/256876

Jaccard, J.; Turrisi, R. 2003. Interaction effects in multiple regression. $2^{\text {nd }}$ ed. Thousand Oaks, CA: Sage Publications. http://dx.doi.org/10.4135/9781412984522

Kassinis, G. I.; Panayiotou, A. 2006. Perceptions matter. CEO perceptions and firm environmental performance, The Journal of Corporate Citizenship 23: 67-80.

http://dx.doi.org/10.9774/GLEAF.4700.2006.au.00009

Kerler, W. A.; Killough, N. L. 2009. The effects of satisfaction with a client's management during a prior audit engagement, trust, and moral reasoning on auditors' perceived risk of management fraud, Journal of Business Ethics 85(2): 109-136. http://dx.doi.org/10.1007/s10551-008-9752-x

Koehn, P. H.; Uitto, J. I. 2014. Evaluating sustainability education: lessons from international development experience, Higher Education 67(5): 621-635.

http://dx.doi.org/10.1007/s10734-013-9669-x

Lounsbury, M. 2001. Institutional sources of practice variation: staffing college and university recycling programs, Administrative Science Quarterly 46(1): 29-56.

http://dx.doi.org/10.2307/2667124 
Mayer, R. C.; Davis, J. H.; Schoorman, F. D. 1995. An integrative model of organizational trust, Academy of Management Review 20(3): 709-734. 10.5465/AMR.

http://dx.doi.org/10.5465/AMR.1995.9508080335

Mitchell, R. K.; Agle, B. R.; Wood, D. J. 1997. Toward a theory of stakeholder identification and salience: defining the principle of who and what really counts, Academy of Management Review 22(4): 853-886. http://dx.doi.org/10.5465/AMR.1997.9711022105

Montgomery, D. B.; Ramus, C. A. 2011. Calibrating MBA job preferences for the 21 st century, Academy of Management Learning \& Education 10(1): 9-26.

http://dx.doi.org/10.2139/ssrn.1077439

Peterson, R. A. 1994. A meta-analysis of Cronbach's coefficient alpha, Journal of Consumer Research 21(2): 381-391. http://dx.doi.org/10.1086/209405

Podsakoff, P. M.; Mackenzie, S. B.; Lee, J. Y.; Podsakoff, N. P. 2003. Common method biases in behavioral research: a critical review of the literature and recommended remedies, Journal of Applied Psychology 88(5): 879-903. http://dx.doi.org/10.1037/0021-9010.88.5.879

Ramus, C. A.; Steger, U. 2000. The roles of supervisory support behaviors and environmental policy in employee "ecoinitiatives" at leading-edge European companies, Academy of Management Journal 43(4): 605-626. http://dx.doi.org/10.2307/1556357

Rousseau, D. M.; Sitkin, S. B.; Burt, R. S.; Camerer, C. 1998. Not so different after all: a crossdiscipline view of trust, Academy of Management Review 23(3): 393-404.

http://dx.doi.org/10.5465/AMR.1998.926617

Rusinko, C. A. 2010. Integrating sustainability in management and business education: a matrix approach, Academy of Management Learning \& Education 9(3): 507-519.

http://dx.doi.org/10.5465/AMLE.2010.53791831

Russo, M. V.; Fouts, P. A. 1997. A resource-based perspective on corporate environmental performance and profitability, Academy of Management Journal 40(3): 534-559.

http://dx.doi.org/10.2307/257052

Schoorman, F. D.; Mayer, R. C.; Davis, J. H. 2007. An integrative model of organizational trust: past, present and future, Academy of Management Review 32(2): 344-354.

http://dx.doi.org/10.5465/AMR.2007.24348410

Serva, M. A.; Fuller, M. A. 2004. The effects of trustworthiness perceptions on the formation of initial trust: Implications for MIS student teams, Journal of Information Systems Education 15(4): 383-395.

Sharma, S. 2013. Pathways of influence for sustainability in business schools: a dean's eye view, Organization \& Environment 26(2): 230-236. http://dx.doi.org/10.1177/1086026613486655

Sharma, S.; Aragón-Correa, J. A.; Rueda-Manzanares, A. 2007. The contingent influence of organizational capabilities on proactive environmental strategy in the service sector: an analysis of North American and European ski resorts, Canadian Journal of Administrative Sciences 24: 268-283. http://dx.doi.org/10.1002/cjas.35

Sharma, S.; Hart, S. L. 2014. Beyond "saddle bag" sustainability for business education, Organization \& Environment 27(1): 10-15. http://dx.doi.org/10.1177/1086026614520713

Sharma, S.; Henriques, I. 2005. Stakeholders influences on sustainability practices in the Canadian forest products industry, Strategic Management Journal 26(2): 159-180.

http://dx.doi.org/10.1002/smj.439

Slater, D.; Dixon-Fowler, H. R. 2010. The future of the planet in the hands of MBAs: an examination of CEO MBA education and corporate environmental performance, Academy of Management Learning \& Education 9(3): 429-441. http://dx.doi.org/10.5465/AMLE.2010.53791825

Stead, J. G.; Stead, W. E. 2010. Sustainability comes to management education and research: a story of coevolution, Academy of Management Education \& Learning 9(3): 488-498.

http://dx.doi.org/10.5465/AMLE.2010.53791829 
Tomlinson, E. C.; Mayer, R. C. 2009. The role of causal attributions dimensions in trust repair, Academy of Management Review 34(1): 85-104. http://dx.doi.org/10.5465/AMR.2009.35713291

United Nations Educational, Scientific and Cultural Organization (UNESCO). 2002. Declaration of the United Nations Decade of Education for Sustainable Development: 2005-2014.

Uslaner, E. M. 2013. Trust as an alternative to risk, Public Choice 157(3/4): 629-639.

http://dx.doi.org/10.1007/s11127-013-0082-x

Wang, J.; Wang, X. 2012. Structural equation modeling: applications using Mplus. West Sussex, UK: Wiley \& Chichester. http://dx.doi.org/10.1002/9781118356258

\section{APPENDIX}

Questionnaires (we are presenting here an English version of the items; original questionnaires were written and administered in the language of the respondents).

\section{DEAN'S QUESTIONNAIRE}

Variable: environmental proactivity of the school.

Assess (by means of a Likert scale from 0 to 6) your intentions in relation to the development of the following environmental practices in your centre.

Existence of specific containers for recycling paper in the building.

Systematic use of recycled paper in the communications and in the centre's offices.

Selective collection program for toner cartridges of printers and copiers.

Installation of sensors for automatic adjustment of the different climate zones.

Existence of automatic lighting of common areas to avoid wastage.

Existence of automatic watering points in common areas to avoid wastage.

Contracting suppliers that have certified environmental management systems.

Encouraging the purchase of computers and electronic equipment that are more environmentally friendly (e.g. eco-labels or with a lower energy consumption).

Own system generating renewable energy (e.g. solar or wind power).

Promotion of sustainable transport by the centre (e.g. parking priority for car sharing or car parks reallocated to bicycles).

Compulsory measures of advanced environmental management for the cafeteria of the centre.

Program to reduce the environmental impact of laboratories or computer rooms.

Program to reduce the use of toxic chemicals or the toxicity of them in the cleaning service.

\section{HEADS OF DEPARTMENT'S QUESTIONNAIRE}

Dependent variable: integration of sustainability into management education. (Construct Reliability $=0.9490$ Average Variance Extracted $=0.7274$ )

Indicate (by means of a Likert scale from 1 to 5) your preferences about the integration of the following content into the courses taught in your department in the future. 
Environmental laws and regulations.

Environmental management systems and certification.

Social responsibility and environmental ethics.

Sustainable production systems and waste management.

Energy saving systems or impact reduction.

Sustainable economy.

Technology for sustainable development.

Independent variables:

Perceived stakeholder benevolence. (Construct Reliability $=0.8915$; Average Variance Extracted $=0.5808)$.

Assess (by means of a Likert scale from 0 to 6 ) the interest of each of the following groups in the introduction or strengthening of topics related to the environment and the sustainability into the syllabuses of the courses taught by your department.

Departmental faculty.

Steering committees of the bachelor degrees.

Students of the courses taught by the department.

University governance team.

Team responsible for the university subjects.

Ecological groups and NGOs.

Perceived stakeholder ability. (Construct Reliability $=0.8790$; Average Variance Extracted $=0.5549$ )

Assess (by means of a Likert scale from 0 to 6) the importance of each of the following groups in the decision making processes of your department.

Departmental faculty.

Steering committees of the bachelor degrees.

Students of the courses taught by the department.

University governance team.

Team responsible for the university subjects.

Ecological groups and NGOs.

Interest in financial aims. (Cronbach's alpha $=0.65$ )

Indicate (by means of a Likert scale from 0 to 6 ) the importance of the following topics in the daily operation of your department.

Operational cost reduction.

Rise in the budget revenues. 
Blanca L. DELGADO-MÁRQUEZ (Prof. Dr). PhD in Economics and Business, University of Granada. She is currently an Associate Professor at the University of Granada (Spain). She is author of a number of articles about social capital (trust, networks) and decision-making processes. She has published in top tier research journals, such as Social Indicators Research, Decision Support Systems, Journal of International Education and Leadership, Journal of Environmental Science and Management, Annals of Operations Research, International Entrepreneurship and Management Journal, and Higher Education, among others.

J. Alberto ARAGÓN-CORREA (Prof. Dr). PhD in Business Administration and Economics, University of Seville. He is a Full Professor of Strategic Management at the University of Granada (Spain) and visiting professor at University of Surrey (UK). His research interests include the connections between natural environment and business strategy. He has published in top tier journals such as Academy of Management Journal, Academy of Management Review, California Management Review, British Journal of Management, Long Range Planning, Journal of Business Research, Ecological Economics, Journal of Environmental Management, Sustainable Development, among others. He has been Deputy Dean in the School of Economics and Business for seven years and Chair of Department of Management at University of Granada. He has lead different research projects supported by the European Commission analyzing how to integrate sustainability in the university. He is Editor-in-chief of the journal Organization \& Environment.

Eulogio CORDÓN-POZO (Prof. Dr). PhD in Business Administration and Economics, University of Granada. He is a Full Professor at the University of Granada (Spain). His research interests include the connections between natural environment and international strategy. He has published in top journals such as Industrial Marketing Management, International Journal of Technology Management and Management Decision, among others. He has participated in different research projects supported by the Spanish Ministry of Education analyzing how to integrate sustainability in the university.

Luis Enrique PEDAUGA (Dr). PhD in Economics, University of Granada. He is an associate lecturer at the University of Granada (Spain). His research interests include the analysis of sustainable issues in the fields both of Management and Economics. He has served as an economist at the Central Bank of Venezuela. He has published in top journals such as Economic Term (Trimestre Económico in Spanish), Spanish Journal of Finance and Accounting, Monetary (Monateria in Spanish), among others. He has participated in different research projects supported by the Spanish Ministry of Education analyzing how to integrate sustainability in the university. 